\title{
DESIGN AND PERFORMANCE ANALYSIS OF B-SERIES PROPELLER FOR TRADITIONAL PURSE SEINE BOAT IN THE NORTH COASTAL REGION OF CENTRAL JAVA INDONESIA
}

\author{
Aulia Windyandari", Gunawan Dwi Haryadi, Suharto Suharto \\ Diponegoro University, Indonesia
}

In the North Coastal Region of Central Java, the traditional fishing boat is a primary object that generates the economics activities of the social community. As an artisanal fishery, the boats generally adopt the tradition to build technique from their predecessor. Therefore the lack of practice to determine the propeller design which considered the hydrodynamic relation within the boat dimension, hull form geometry and propeller is observed. Presently, there is no a standard propeller design that particularly well designed considering the hull shape geometry for the traditional boat. The aim of the research is to identify the propeller that would be applied to the fishing boats typically found in the North Coastal Region of Central Java using B-Series marine propeller. Computational Fluid Dynamics (CFD) analysis for assessing the performance ofthrust and torque of the developed propeller was performed.

Key words: Wageningen B-series propeller; Traditional purse seine boat; Thrust propeller; Propeller efficiency

\section{INTRODUCTION}

The North Coastal of Central Java is the second largest fishery community region in Indonesia. More than 200.000 peoples have a livelihood as fishermen, and others have jobs related to the fishing industry such as fishing port and boatyard. Therefore the central java has a large number of fishing boat fleet that is about 8000 boats to support the fishing activities of them, [1]. The traditional fishing boats generally constructed by boat builders and boat yards that are located on the coastal region. Most of the boat builders use their own skill that is adopted from the tradition to build technique of their predecessors.Although they do not have any knowledge of basic principle of naval architecture and marine engineering, the boat building technique allow them to create a robust boats for their fishing region. However it is observed that there is a problem of the lack of practice to determine the propeller design which considered the hydrodynamic relation within the boat dimension, hull form geometry and propeller.Therefore, in order to improve propulsion efficiency of this type of boats, contemporary engineering methods should be applied.

The process of propeller design is a complex procedure where the viscous flow around the propeller and the cavitation effect should be considered[2], [3]. Propeller design process is also constrained by some hydrodynamics parameters such as Reynolds number, and maximum diameter in the case of weight loading,[4].Since water density is larger than air,therefore the ability to generate the lift force for thrust on the unit of blade area is also limited. Whiletheoretical method offer consistently precision of the design of propeller, however it is quitedifficult to develop, [5], [6].
During the design phase, some critical parameters such as rake, skew, and pitch angles should be determined. Small magnitude of rake might reduce the drag force on the blade surface and increase the thrust force and the propeller efficiency, [7]. The formation of skews providesstability, however, the vibration of propulsion system might be occurred due to the low magnitude of skew angle. Pitch angle is a helix angle of the rotating propeller that influences the magnitude of propeller pitch. Pitch is the axial distance made by a propeller in a complete spin of 360 degrees, at zero thrust and zero slip. The increase of pitch, to the same propeller diameter, might reduce the interaction area with inflow fluid, however it mightincrease the face interaction to the rotational motion, [8]. The large blade area will increase the sweeping area of the water surface. Besides, the increase of blade area may cause higher torque,[9], and reduces the efficiency of the peak performance, [10].

Nowadays new marine propellers designs are created with the application of computational fluid dynamics (CFD) analysis. In the CFD Analysis, Navier-Stokes equation is adopted to solve the nonlinear flow of the marine propeller. Some studies of CFD application on the marine propeller can be found. Shotaro, U., studied on the application of CFD to the computation of the flow around a marine propeller, [11]. A marine propeller model is developed using Implicit Geometrical Method. The results show a good agreement for chord wise load distribution, thrust and torque coefficient with Lifting Surface Method, [11].Watanabe, T., investigate the thrust and torque coefficient using Reynolds Averaged Navier-Stokes (RANS) simulations of flow on the two different conventional propellers and the RANS approach have a good agreement with experimental measurement,[12]. 
Rhee, S. H. proposed a hybrid mesh generation strategy and validate computational result of an unstructured mesh based RANS method, [13]. It is found that the thrust and torque are in agood agreement with the experimental value. Wu, X. extend the OpenPVL code to accomplished the propeller thrust simulation and strength evaluation. The result shows that OpenPVL_SW code provides an acceptable simulation result of thrust and present the perfect geometry of propeller,[14]. Liu, D. C. investigate the marine propeller cavitating and open water performance using an unstructured mesh based RANS solver,[15].Subhas, S. investigate the thrust and torque in open water with varying speed of advance and revolution rate,[16].Sun, S. analyzes the propeller exciting force characteristics and the interaction of hull, propeller and rudder using CFD Analysis,[17].

All mentioned studies have shown that CFD analysis might bea reliable method to evaluate the propeller performances. Therefore the aim of the research is to develop standard propellers that would be applied to the fishing boats typically found in the North Coastal Region of Central Java,based onB-Series marine propellers, using CFD analysis.Wageningen B-Series propellers are selected asthe standard design since many boat wassuccessfully adopted the series for its efficient propulsion system.

\section{The Wageningen B-Screw Series Propeller}

B-Series propeller was introduced by Troost, [18], [19], [20]. After that the series have been re-appraisal with the different test procedures, and the results were presented by Van Lammeren,[21]. For the use of computational studies, in the preliminary ship design phase, the open water characteristicsof the B-Series are defined in polynomial form. The multiple regression analysis of 120 models propeller data was used to determine the polynomials function. At a Reynolds number $\left(R_{n}\right) 2 \times 106$, the open water characteristicsof the B-Series, the thrust coefficient $\left(K_{T}\right)$ and the torque coefficient $\left(K_{Q}\right)$, are defined by the equation as follows:

Where $C_{T n}, C_{Q n}, S_{n}, t_{n}, u_{n}$ and $v_{n}$ are regression coefficients, $J$ is advanced coefficient, $P / D$ is propeller pitch ratio, $A_{E} / A_{0}$ is ratio of blade area and $Z$ is the number of the propeller blades.

$K_{T}=\sum_{n=1}^{39} C_{T n} J^{S n}\left(\frac{P}{D}\right)^{t n}\left(\frac{A_{E}}{A_{0}}\right)^{u n} Z^{v n}$

$K_{Q}=\sum_{n=1}^{47} C_{Q n} J^{S n}\left(\frac{P}{D}\right)^{t n}\left(\frac{A_{E}}{A_{0}}\right)^{u n} Z^{v n}$

For other Reynolds numbers with interval between $2 \times 106$ - $2 \times 109$, the set of correction should be given as follows: Where $\Delta K_{T}$ is the thrust correction factor, and $\Delta K_{Q}$ is the torque correction factor. The values of coefficients and correction factors in above equationsare given in[9]. The geometry of expanded surface ofpropeller bladesis given in theTable 1 . The propeller pitch ratio $(P / D)$ is defined within 0.6 to 1.4 . Generally the B-Series propeller is denoted by $B Z-y$, where BforB-Series,

Table 1: Overall geometry properties of B-Series Propellers, [9]

\begin{tabular}{|c|c|c|c|c|c|c|c|c|}
\hline \multirow{2}{*}{$r / R$} & \multicolumn{3}{|c|}{$\begin{array}{l}\text { Parameters of four-bladed to } \\
\text { seven-bladed propellers }\end{array}$} & \multicolumn{3}{|c|}{$\begin{array}{l}\text { Parameters of three-bladed } \\
\text { propellers }\end{array}$} & \multicolumn{2}{|c|}{$t / D=A_{r}-B, Z$} \\
\hline & $\begin{array}{c}c / D^{*} \\
Z /\left(A_{E} / A_{O}\right)\end{array}$ & $a / c$ & $b / c$ & $\begin{array}{c}c / D^{*} \\
Z /\left(A_{E} / A_{O}\right)\end{array}$ & $a / c$ & $b / c$ & $A_{r}$ & $B_{r}$ \\
\hline 0.2 & 1.662 & 0.617 & 0.350 & 1.633 & 0.616 & 0.350 & 0.0526 & 0.0040 \\
\hline 0.3 & 1.882 & 0.613 & 0.350 & 1.832 & 0.611 & 0.350 & 0.0464 & 0.0035 \\
\hline 0.4 & 2.050 & 0.601 & 0.351 & 2.000 & 0.599 & 0.350 & 0.0402 & 0.0030 \\
\hline 0.5 & 2.152 & 0.586 & 0.355 & 2.120 & 0.583 & 0.355 & 0.0340 & 0.0025 \\
\hline 0.6 & 2.187 & 0.561 & 0.389 & 2.186 & 0.558 & 0.389 & 0.0278 & 0.0020 \\
\hline 0.7 & 2.144 & 0.524 & 0.443 & 2.168 & 0.526 & 0.442 & 0.0217 & 0.0015 \\
\hline 0.8 & 1.970 & 0.463 & 0.479 & 2.127 & 0.481 & 0.478 & 0.0154 & 0.0010 \\
\hline 0.9 & 1.582 & 0.351 & 0.500 & 1.657 & 0.400 & 0.500 & 0.0092 & 0.0005 \\
\hline 1.00 & 0.000 & 0.000 & 0.000 & 0.000 & 0.000 & 0.000 & 0.000 & 0.000 \\
\hline
\end{tabular}

$A_{r}, B_{r} \quad$ - constants value of $t / D$ equation

a - distance of leading edge to generator line at $r$

b - distance of leading edge to maximum thickness location

c $\quad$ - length of blade section cord at radius $r$

$t$ - maximum thickness of blade section at radius $r$ 
$Z$ is number of blades, and $y$ is propeller area ratio.

$$
\left\{\begin{array}{l}
K_{T}\left(R_{n}\right) \\
K_{Q}\left(R_{n}\right)
\end{array}\right\}=\left\{\begin{array}{l}
K_{T}\left(R_{n}=2 \times 10^{6}\right) \\
K_{Q}\left(R_{n}=2 \times 10^{6}\right)
\end{array}\right\}+\left\{\begin{array}{l}
\Delta K_{T}\left(R_{n}\right) \\
\Delta K_{Q}\left(R_{n}\right)
\end{array}\right\}(2)
$$

Coordinates of the blade sections, which can be seen in Figure 1, are calculated by the formula that is given by Van Gent and Van Oossanen, [22], Oossanen, [23]. The detail values of $V_{1}, V_{2}$ can be obtained in [9], and the values of $t_{(t . e)}, t_{(\text {(.e) }}$ are generally determined in accordance with the classifications regulation or the manufacturing requirements.
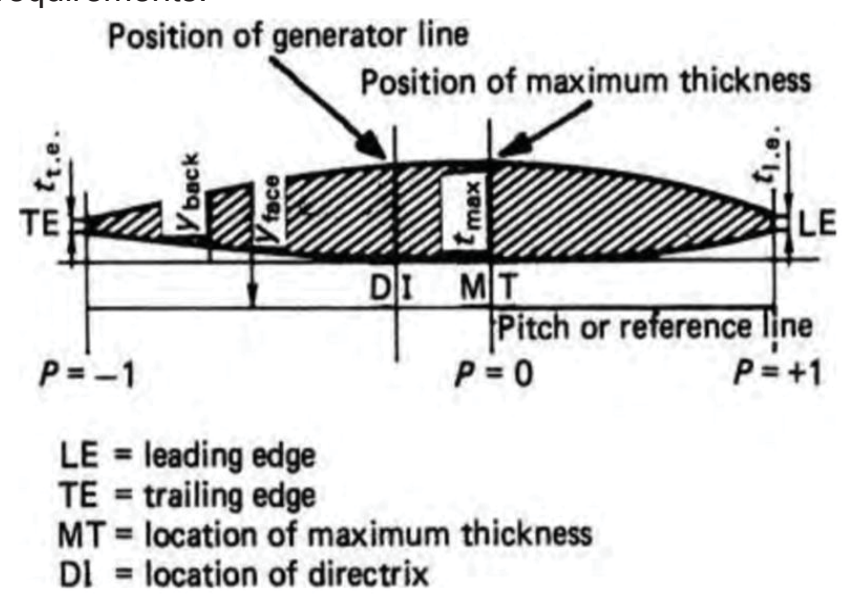

Figure 1: Geometry of blade sections, [9]

$\left.\begin{array}{c}Y_{\text {face }}=V_{1}\left(t_{\text {max }}-t_{\text {t.e }}\right) \\ Y_{\text {back }}=\left(V_{1}+V_{2}\right)\left(t_{\text {max }}-t_{\text {t.e }}\right)\end{array}\right\}$ for $P \leq 0$

$\left.\begin{array}{c}Y_{\text {face }}=V_{1}\left(t_{\text {max }}-t_{\text {l.e }}\right) \\ Y_{\text {back }}=\left(V_{1}+V_{2}\right)\left(t_{\text {max }}-t_{\text {l.e }}\right)\end{array}\right\}$ for $P \geq 0$

Where,

$Y_{\text {face }}, Y_{\text {back }}$ - ordinate of the face point and the back point with respect to pitch line

$\mathrm{t}_{\max }$ - blade section maximum thickness

$t_{\text {(t.e) }}, t_{(1 . e)}$ - extrapolated blade section thickness at the trailing and leading edge

$\mathrm{V}_{1}, \mathrm{~V}_{2}$ - constants value are subjected to $r / R$ and $P$

$P$ - normalized abscissa of blade section

\section{DESIGN AND SIMULATION MODELING OF B-SERIES PROPELLER FOR TRADITIONAL PURSE SEINE BOAT}

\section{Design process of the boat propeller}

Regarding the research objective to obtain the appropriate design of marine propeller for traditional boat in the North Coastal region of Central Java, the technical survey that involved the boat owners, the boat yards and the propeller producers was made. The documented survey data generally providedthe general specifications of boats, the specification of main propulsion engines, and the propellers specifications. Based on the boat size,all collected boatscan be categorized on the two groups: below 30 Gross Tonnage (GT) and more than 30 GT.
The research will be focused on the propeller design for the first group.The collected data of propeller specification show that diameters of these propellers are in range of $20 \mathrm{~cm}$ to $40 \mathrm{~cm}$ with the blade numbers mostly of 3-blades and some of them use 2-blades or 4-blades. Recently, the boat propeller selection is usually determined by the available propeller spare parts on the local market. According to the collected data the hydrodynamic relation of the boat hull form and propeller is not considered. Consequently, the boats have limitations regarding propulsion efficiency, as well as hull vibration, overheat main engine and high fuel consumption.

Initially, the boat hull form is selected as a representation of the boats population. The selection criteria of the hull forms have been discussed with the boat owners and communities, such as: the size of the ship, the stern shape geometry, the type of fishing gear, the number of ship in the population and the propulsion system type. In the next stepsizeof the boat is chosen, and the hull form is generated for the prediction of the boat resistance by creating the lines plan with the ordinates data from the measurement of the boat hull. Modification and smoothing procedure was made, finally the generated lines plan was verified with the actual shape of the ship hullform. Besides the resistance characteristics, the boat stern shape is also important factor for propeller design as the requirement of the propeller clearance that can be found in [24].The characteristics of the selected boat are shown in Table 2.

Table 2: The traditional purse seine boat characteristics

\begin{tabular}{|l|c|}
\hline \multicolumn{1}{|c|}{ Boat design parameters } & Dimension \\
\hline Length of Perpendicular (Lpp) & $13.1 \mathrm{~m}$ \\
\hline Breadth & $4.15 \mathrm{~m}$ \\
\hline Draft & $1.56 \mathrm{~m}$ \\
\hline Height & $1.97 \mathrm{~m}$ \\
\hline Block Coefficient & 0.53 \\
\hline Service speed & $9 \mathrm{knot}$ \\
\hline Total Resistance & $15.18 \mathrm{~kW}$ \\
\hline Wake Fraction & 0.15 \\
\hline Number of propeller & Single Screw \\
\hline Height of propeller aperture & $1.20 \mathrm{~m}$ \\
\hline Thrust deduction & 0.12 \\
\hline
\end{tabular}

Since the hull form hasbeen determined, the next procedure is to find the optimum B-series propeller diameter $(D)$, and other parameters: Area Ratio $\left(A_{E} / A_{0}\right)$, Pitch Ratio $(P / D)$ and Advanced Coefficient $(J)$. Considering the vibration of the hull, the propeller diameter is constrained by the propeller clearance regulation, [23]. The optimization computation was made using computer program that was developed by defining the objective function and constraints. The optimum parameters will be discovered for propellers with 3, 4, 5 and 6 blades were considered. The detailed optimization algorithm can be found in [25]. The optimization procedure results of the boat propellers can be seen on the Table 3 . 


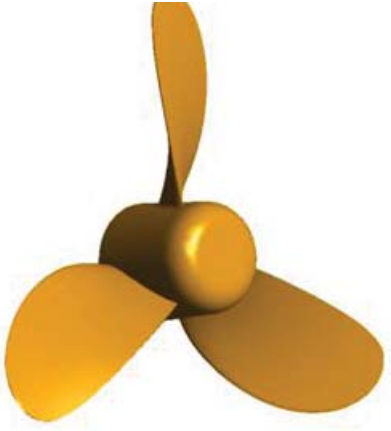

[a]

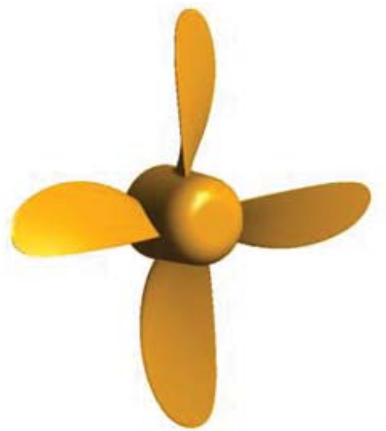

[b]

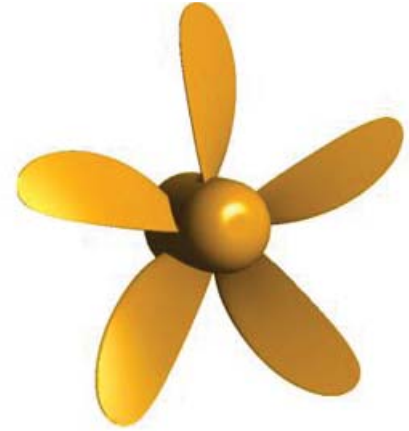

[c]

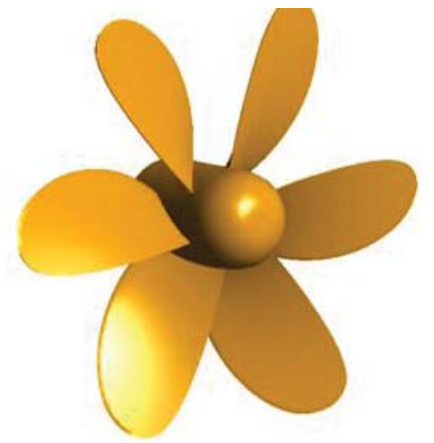

[d]

Figure 2: 3D-model of the boat propellers: [a] 3-bladed; [b] 4-bladed; [c] 5-bladed; [d] 6-bladed

Table 3: The optimum parameters of the boat propellers

\begin{tabular}{|c|c|c|c|c|}
\hline $\begin{array}{c}\text { Design } \\
\text { Parameters }\end{array}$ & 3-Bladed & 4-Bladed & 5-Bladed & 6-Bladed \\
\hline $\begin{array}{c}\text { Propeller } \\
\text { Diameter }(\mathrm{D})\end{array}$ & $0.894 \mathrm{~m}$ & $0.881 \mathrm{~m}$ & $0.764 \mathrm{~m}$ & $0.582 \mathrm{~m}$ \\
\hline $\begin{array}{c}\text { Area Ratio } \\
\left(\mathrm{A}_{\mathrm{E}} / \mathrm{A}_{\mathrm{O}}\right)\end{array}$ & 0.298 & 0.315 & 0.371 & 0.527 \\
\hline $\begin{array}{c}\text { Pitch Ratio } \\
(\mathrm{P} / \mathrm{D})\end{array}$ & 0.917 & 0.917 & 0.676 & 0.526 \\
\hline $\begin{array}{c}\text { Advanced } \\
\text { Coefficient }(\mathrm{J})\end{array}$ & 0.686 & 0.697 & 0.525 & 0.375 \\
\hline $\begin{array}{c}\text { Propeller } \\
\text { revolution }(\mathrm{n})\end{array}$ & $6.42 \mathrm{rps}$ & $6.42 \mathrm{rps}$ & $9.82 \mathrm{rps}$ & $18.03 \mathrm{rps}$ \\
\hline $\begin{array}{c}\text { Propeller } \\
\text { efficiency }(\mathrm{\eta})\end{array}$ & 0.706 & 0.662 & 0.567 & 0.474 \\
\hline
\end{tabular}

The optimum parameters is used as a reference for the preliminary design of the propeller blade geometry which can be evaluated with respect to the thrust efficiency, the cavitation characteristics and the flow patterns behavior. The design of the boat propeller is developed using computer aided design (CAD) software, through the standard blade coordinates of the B-Series. The additional design data should be given which consisted of the rake angle, the skew angle of propeller and the hub diameter. Since all of design parameters is defined, the three dimensional blades are drawn and the two dimensional propeller technical drawing can be generated. The three dimensional propeller design model can be seen on the Fig. 2. The technical drawing of the 4-bladed propeller is presented in the Fig. 3.

\section{Description of simulation modeling}

The model of simulation is considered as an enclosed cylindrical fluid domain. The axial up stream is defined at the inlet, while the outlet is defined as a downstream with the distance about six times of propeller diameter. The solid element is used as the propellers model and it is located at the center of the coordinate system origin which is aligned with the fluid inflow. The outer boundary domain is defined with the distance about the 1.5 of propeller diameterfrom the origin, see Fig. 4. Since most of researches adopted the unstructured grids for the CFD analysis model, therefore the unstructured grids are used for the model computation, see Fig. 5.

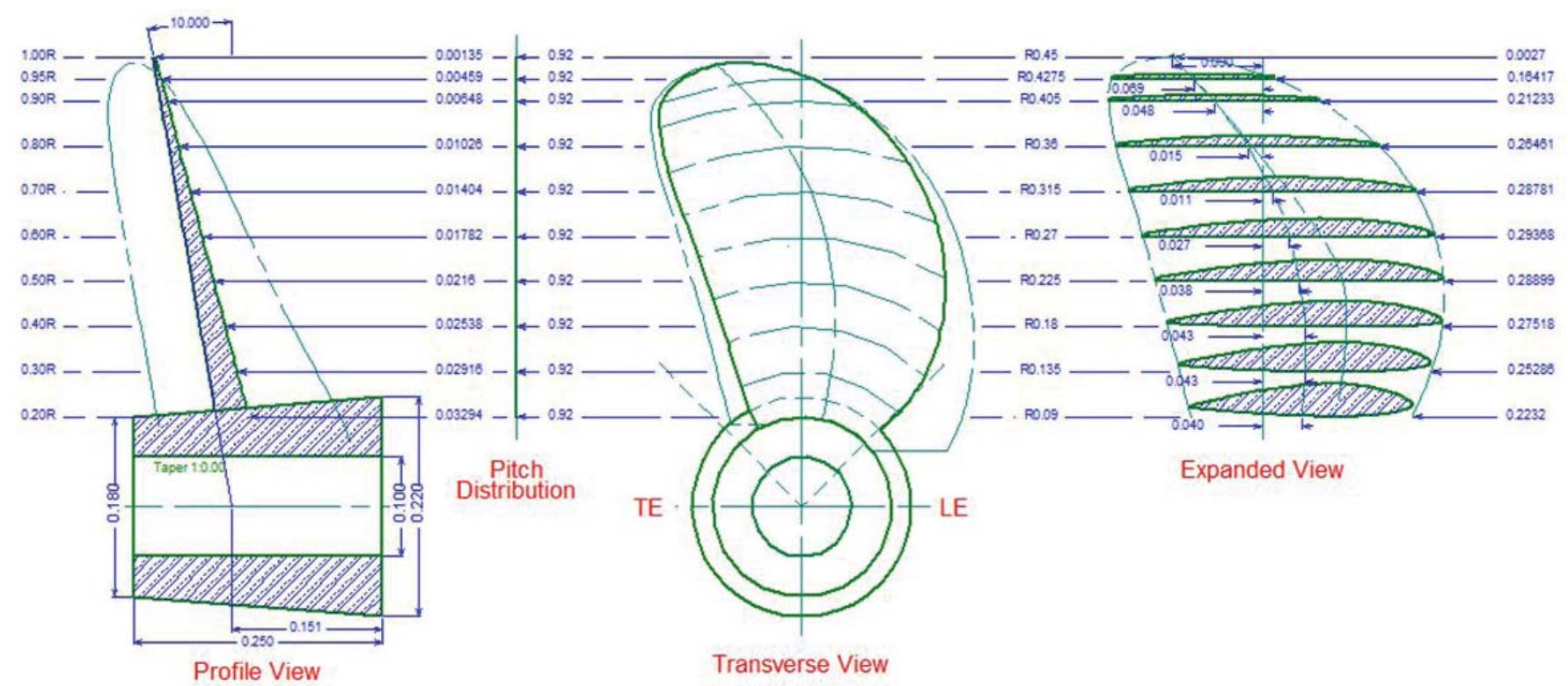

Figure 3: 2-D technical drawing of the proposed 4-bladed propeller 


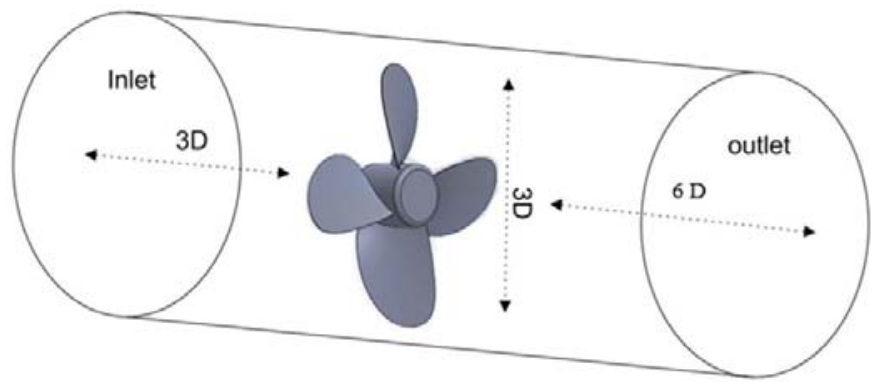

Figure 4: The size of CFD analysis domain

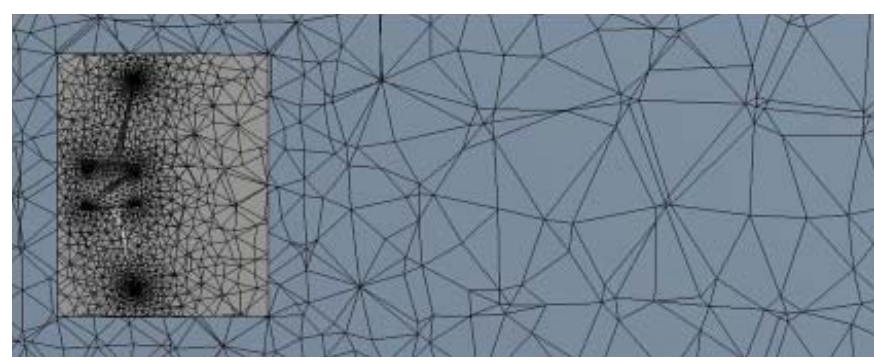

Figure 5: Unstructured grid meshing model

The boundary condition is defined applied to the wall, flow velocity at the inlet and outflow on the simulation domain. The inlet boundary condition is used to determine the velocity of the fluid flow while entry the propellers. The velocity magnitude has normal direction on the inlet boundary surface. Otherwise the outflow boundary condition was defined to model the exit behavior of the fluid flow on the outlet. The outflow boundaries are not defined specifically since the outflow velocity isdepending on the updated flow condition during the simulation. The fully developed flow is assumed on the updated flow velocity and pressure behavior. On the vicinity of wall the Reynolds number is very low and the fluctuations of fluid turbulent are considerably constrained.

Table 4: Domain Parameters

\begin{tabular}{|l|l|}
\hline \multicolumn{1}{|c|}{ Parameters } & \multicolumn{1}{c|}{ Settings } \\
\hline Type & Fluid \\
\hline Materials & Water \\
\hline Buoyancy Model & Non Buoyant \\
\hline Domain Motion & Rotating \\
\hline Reference Pressure & 1 Atm \\
\hline Heat Transfer Model & Isothermal \\
\hline Fluid Temperature & $25^{\circ}$ \\
\hline Density of Fluid & $1025 \mathrm{~kg} / \mathrm{m}^{3}($ Seawater $)$ \\
\hline Viscosity of Fluid & $0.001003 \mathrm{~kg} / \mathrm{m}-\mathrm{s}$ \\
\hline Model of Turbulence & k-epsilon \\
\hline Turbulent Wall Function & Scalable \\
\hline \hline
\end{tabular}

No slip condition is defined on the propeller blade, therefore the drag and lift forces can be calculated and generated the torque and the thrust of the propellers. The no slip condition also be defined on the lateral surface of the fluid domain, consequently the boundary does not have an effect on the propeller rotation simulation. The domain parameters and boundary conditions might be seen on the Table 4 and Table 5, respectively.

\section{RESULTS AND DISCUSSIONS}

According to the simulation results it can be seen that the propeller faces have a different pressure with the back Table 5: Boundary Conditions

\begin{tabular}{|l|l|}
\hline \multicolumn{1}{|c||}{ Location of Boundary } & \multicolumn{1}{c|}{ Conditions } \\
\hline Propeller Blade Surface & No Slip \\
\hline $\begin{array}{l}\text { Lateral surface of the } \\
\text { domain }\end{array}$ & No Slip \\
\hline $\begin{array}{l}\text { Inlet / inflow } \\
\text { condition }\end{array}$ & $\begin{array}{l}7.65 \text { knot } \\
\text { (Advanced velocity) }\end{array}$ \\
\hline Outlet / outflow condition & Outflow \\
\hline
\end{tabular}

region of propeller. The distinct pressures distribution has been integrated and the propeller thrust is obtained. It is shown that the propeller thrust of the proposed propellers is $3.756 \mathrm{kN}, 3.462 \mathrm{kN}, 4.045 \mathrm{kN}$ and $3.746 \mathrm{kN}$ for 3-bladed, 4-bladed, 5-bladed and 6-bladed propeller, respectively. Compared to the methodical series data, the thrust force which is obtained from the simulation has lower magnitude, see Table 6 . It might be explained that the unstructured grid would generate unsteady flow during the simulation. Therefore it may decrease the magnitude of the thrust. Fig. 6 and Fig. 7 show the hydrodynamic pressure contour of the face side and back side of the four propellers, respectively. According to the figures, the hydrodynamic pressures have inevitably negative values. It is indicated that the back side pressure is lower than the ambient pressure. Otherwise a different tendency is shown on the face side pressure which the positive value is obtained as a representation of the face side pressure is larger than ambient pressure.

The cavitation characteristics also can be seen on the Fig. 7. According to the figure, it can be found that the tip cavitation is occurred on all of the propeller design which is shown in the cyan color. Cavitation phenomenon is occurred since the pressures on the back side have significantly decreased until reach the negative pressure which might produce gas on the fluid. Based on the simulation result the magnitude of negative pressure of the proposed propellers design is $-8.55 \times 104 \mathrm{~Pa},-6.65 \times 104 \mathrm{~Pa}$, $-1.04 \times 105 \mathrm{~Pa}$, and $-1.24 \times 105 \mathrm{~Pa}$ for 3-bladed, 4-bladed, 5-bladed and 6-bladed propeller, respectively. Therefore it might be concluded that the 3-bladed propeller has better performance than the other in the case of cavitation 


\section{characteristics.}

The flow trajectories are consisted of inflow and outflow. According to Fig. 8 it can be seen that the fluid swirling is occurred on the face surface of the propellers. The swirling condition is increased when the number of the blades of propellers is increased. The vortex phenomena might be appeared because of the low passed of inflow and the cutting capacity of the propeller blades which provide high magnitude for the higher number of blades propeller. As can be seen on the Fig 8(d), the number of swirling pattern of 6 -bladed propeller is larger than the swirling pattern of 3-bladed and 4-bladed propeller. Therefore the 3-bladed and 4-bladed propeller shows better efficiency of propeller than 5-bladed and 6-bladed propeller. It might be concluded that the larger number of swirling pattern have negative influence to the efficiency of the propeller. Although the 5-bladed and 6-bladed propellers have lower efficiency than the two others, however the 5-bladed and 6-bladed propellers have larger
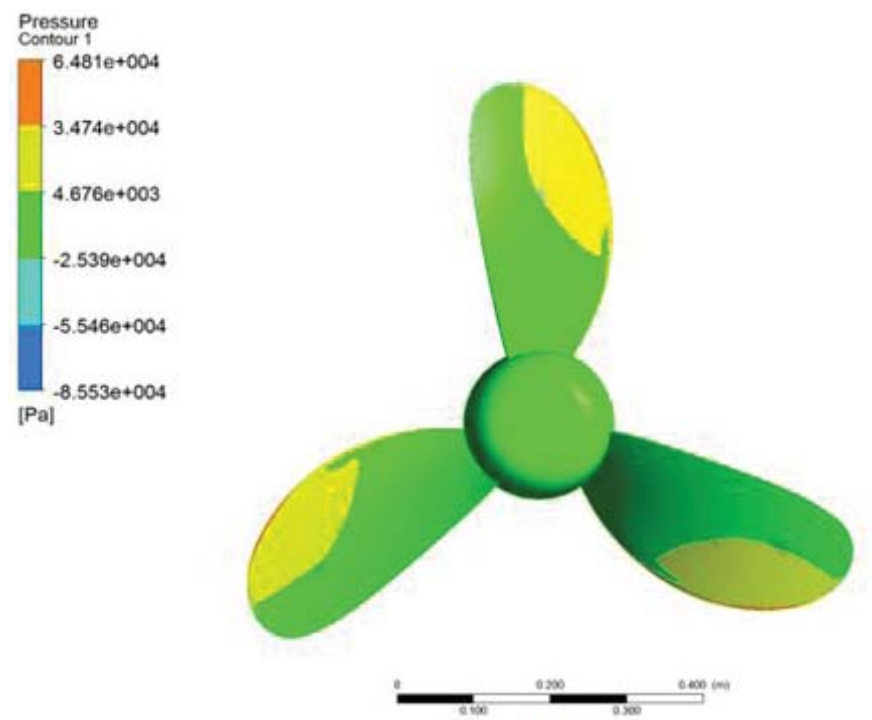

[a]
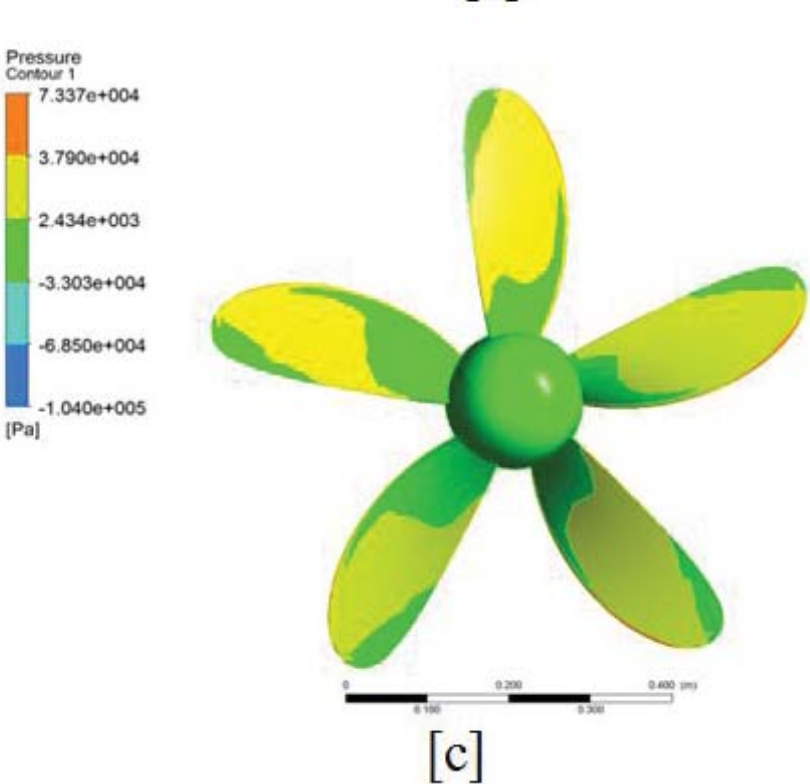

thrust coefficient which indicate the ability to generate the larger thrust force than the 3-bladed and 4-bladed propellers.

\section{CONCLUSIONS}

The standard propeller design using B-series was successfully developed to support the propulsion system of traditional purse seine boat in the North Coastal Region of Central Java Indonesia. The developed propeller design characteristics have been analyzed using CFD analysis and simulation. The unstructured grid mesh was adopted for the modeling process of the open water test propeller simulation. The simulation results show good agreement with the open water characteristics of the methodical B-Series propeller data. In the case of thrust force which provides the propulsion power of the boat, the maximum thrust forceof $3.746 \mathrm{kN}$ is obtained on the 6-bladed propeller.
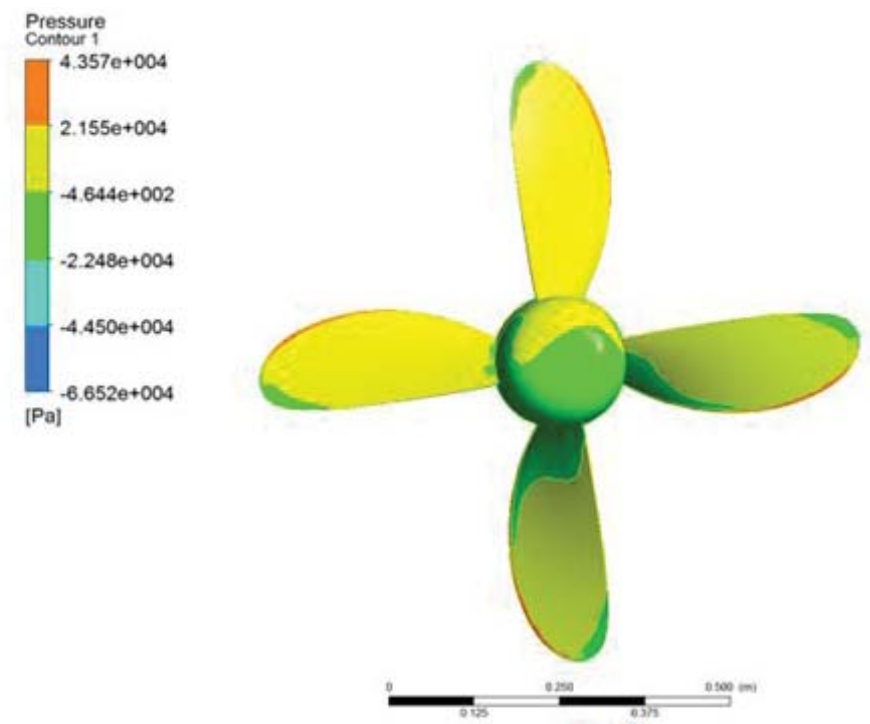

[b]
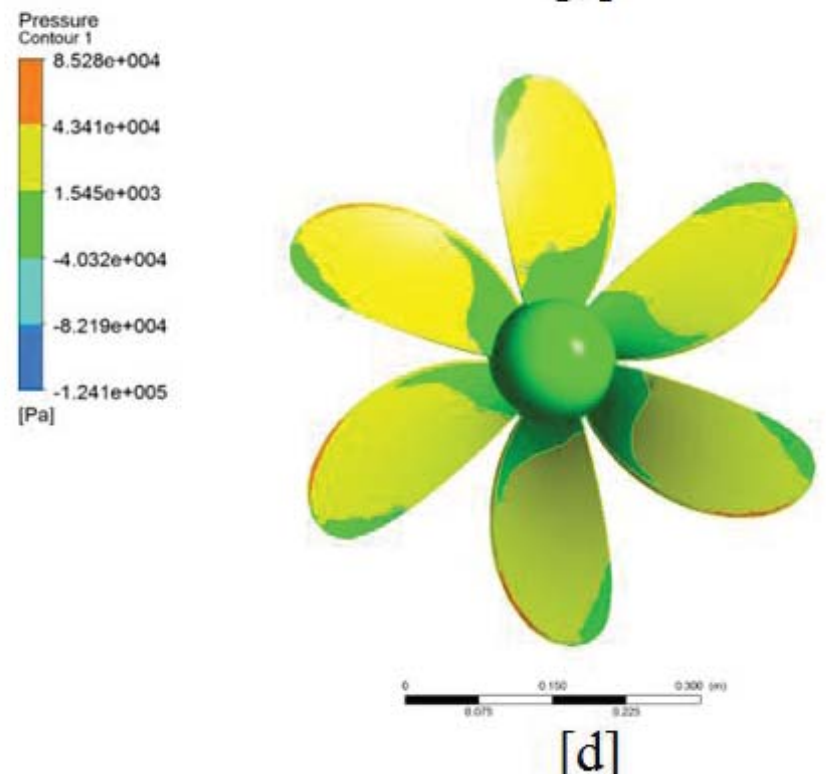

Figure 6: The pressures distribution on the face side of the propellers 

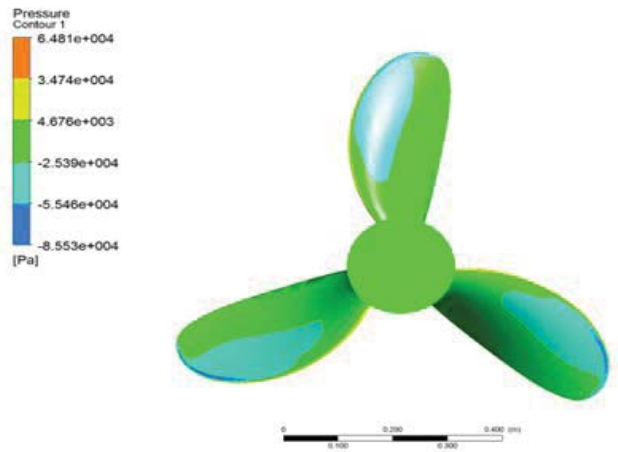

[a]
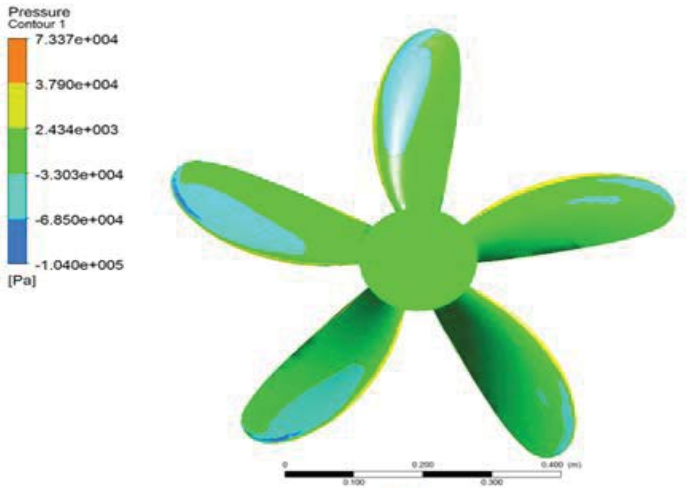

[c]

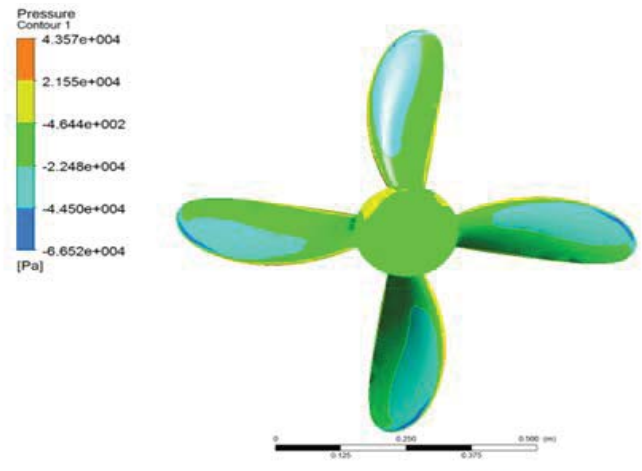

[b]
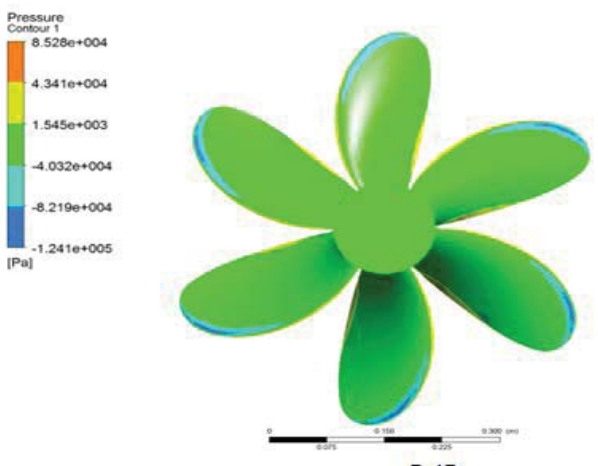

[d]

Figure 7: The pressures distribution on the back side of the propellers
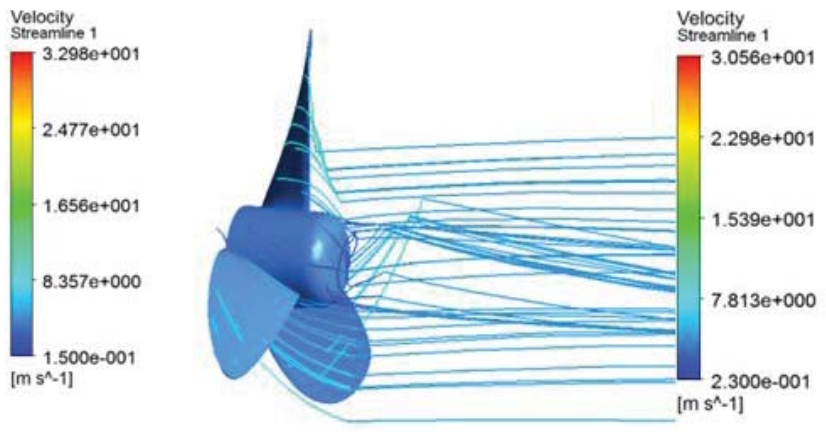

[a]

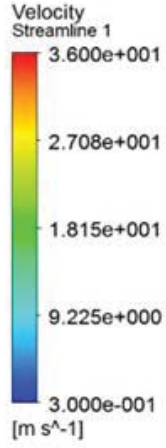

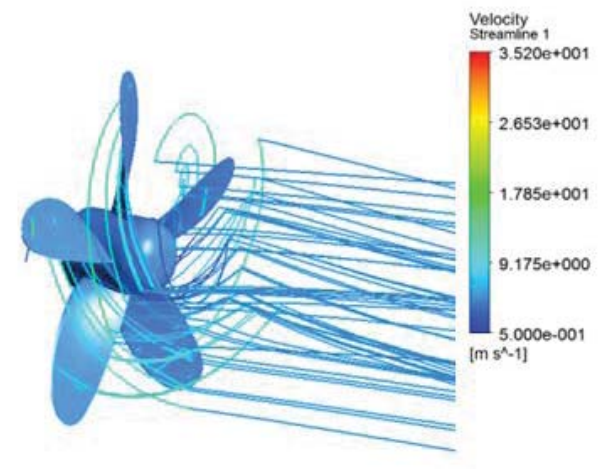

[c]

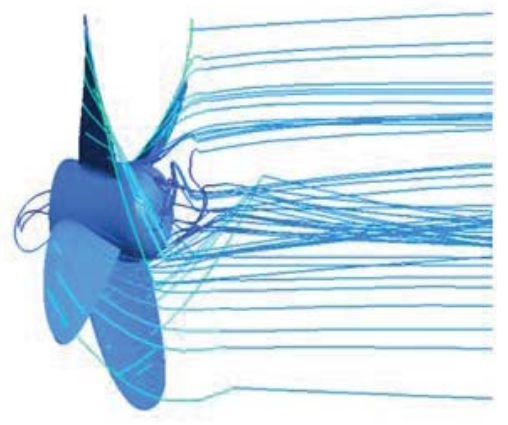

[b]

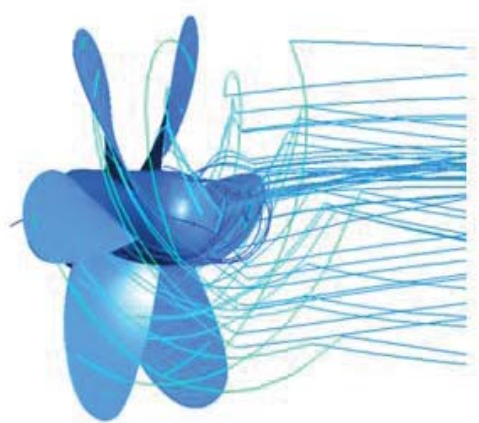

[d]

Figure 8: The flow pattern on the face side of the propellers 
Table 6: Comparison of CFD results with the experimental results

\begin{tabular}{|c|c|c|c|}
\hline Number of Blade & Items & CFD & Data Series \\
\hline \multirow{5}{*}{3 Bladed Propeller } & Advance Coefficient $(\mathrm{J})$ & 0.686 & 0.686 \\
\hline & Thrust Force (kN) & 3.456 & 3.766 \\
\hline & Thrust Coefficient (KT) & 0.18 & 0.14 \\
\hline & Torque Coefficient (10.KQ) & 0.28 & 0.22 \\
\hline & Efficiency ( $\eta)$ & 0.70 & 0.706 \\
\hline \multirow{5}{*}{4 Bladed Propeller } & Advance Coefficient $(\mathrm{J})$ & 0.697 & 0.697 \\
\hline & Thrust Force (kN) & 3.462 & 3.801 \\
\hline & Thrust Coefficient (KT) & 0.20 & 0.15 \\
\hline & Torque Coefficient (10.KQ) & 0.35 & 0.25 \\
\hline & Efficiency $(\eta)$ & 0.66 & 0.662 \\
\hline \multirow{5}{*}{5 Bladed Propeller } & Advance Coefficient $(\mathrm{J})$ & 0.525 & 0.525 \\
\hline & Thrust Force $(\mathrm{kN})$ & 3.645 & 3.823 \\
\hline & Thrust Coefficient (KT) & 0.20 & 0.114 \\
\hline & Torque Coefficient (10.KQ) & 0.30 & 0.17 \\
\hline & Efficiency ( $(\eta)$ & 0.56 & 0.567 \\
\hline \multirow{5}{*}{6 Bladed Propeller } & Advance Coefficient $(\mathrm{J})$ & 0.375 & 0.375 \\
\hline & Thrust Force (kN) & 3.746 & 3.872 \\
\hline & Thrust Coefficient (KT) & 0.26 & 0.102 \\
\hline & Torque Coefficient (10.KQ) & 0.39 & 0.13 \\
\hline & Efficiency ( $\eta)$ & 0.49 & 0.474 \\
\hline
\end{tabular}

Although the maximum thrust force is provides by the 6-bladed propeller, however the maximum torque moment is occurred on the propeller. It might be identified that having the maximum thrust force of the 6-bladed propeller will need more propulsion power and fuel consumption than the 3-bladed propeller design. Since the maximum propeller efficiency is achieved by the 3-bladed propeller, it might be concluded that the 3-bladed propeller is the optimum propeller design for the traditional purse seine boat.

\section{REFERENCES}

1. Triarso, I. (2012). Potential and Opportunity of Fishery Business Development at the North Coast of Central Java translated from Indonesia language. Jurnal Saintek Perikanan, vol. 8, no. 1, 65-73.

2. Morgut, M., Noblie, E. (2012). Influence of Grid Type and Turbulence Model on the Numerical Prediction of the Flow Around Marine Propellers Working in Uniform Inflow.Ocean Engineering, vol. 42, 26-34, DOI: 10.1016/j.oceaneng.2012.01.012

3. Zhu, Z. (2015). Numerical Study on Characteristics Correlation between Cavitating Flow and Skew of Ship Propellers. Ocean Engineering, vol. 99, 63-71, DOI: 10.1016/j.oceaneng.2014.12.023

4. Justin, E. (1986). Marine Propellers. Annual Review of Fluid Mechanics, vol. 18, 367-403, DOI: 10.1146/ annurev.fl.18.010186.002055

5. Takinaci, A.C., Atlar, M. (2002). Performance Assessment of A Concept Propulsor: the Thrust-balanced Propeller. Ocean Engineering, vol. 29, 129149, DOI: 10.1016/S0029-8018(01)00005-1

6. Sánchez-Caja, A., González-Adalid, A., Pérez-Sobrino,M., Sipilä,T. (2014). Scale Efects on Tip Loaded Propeller Performance using a RANSE Solver. Ocean Engineering, vol. 88, 607-617, DOI:10.1016/j. oceaneng.2014.04.029

7. Ghassemi, H. (2009). The Effect of Wake Flow and Skew Angle on the Ship Propeller Performance. Trans. B. Mech. Eng, vol. 16, 129-158

8. Bernitsas, M. M., Ray, D. (1982). Optimal Revolution B-Series Propellers. College of Engineeering The University of Michigan Ann Arbor, Michigan.

9. Oosterveld, M. W. C., Van Ossannen, P. (1975). Further Computer-Analyzed Data of Wageningen B-Screw Series . International Ship Building Progress, vol. 22, no. 251, 3-14

10. Tsakonas, S., Jacobs, W. R., Ali, M. R. (1972). An Exact Linear Lifting-Surface Theory for a Marine Propeller in a Nonuniform Flow Field. New Jersey

11. Shotaro, U., Yoshiaki, K. (1992). Application of CFD 
to the Flow Computation around a Marine Propeller. J. Kansai Soc. N. A., vol. 218, 171-180

12. Watanabe, T., Kawamura, T., Takekoshi, Y., Maeda, M., Rhee,S. H. (2003). Simulation of Steady and Unsteady Cavitation on A Marine Propeller using A RANS CFD Code. in Fifth International Symposium on Cavitation, 1-8

13. Rhee, S. H.Joshi, S. (2005). Computational Validation for Flow around a Marine Propeller Using Unstructured Mesh Based Navier-Stokes Solver. JSME International Journal, vol. 48, no. 3, 562-570

14. Wu, X. (2010). A Rapid Development Process for Marine Propellers Through Design, Simulation and Prototyping. M. Eng Thesis

15. Liu, D. C., Hong, F. W., Zhang, Z. R., Liu, H.(2009). The CFD Analysis of Propeller Sheet cavitation. ship science and technology

16. Subhas, S., Saji, V. F., Ramakrishna, S., Das, H. N. (2012). CFD Analysis of A Propeller Flow and Cavitation. International Journal of Computer Applications, vol. 55 , no. $16,26-33$

17. Sun, S., Wang, C.,Zhang, H.(2018). Numerical Prediction Analysis of Propeller Exciting Force for Hull-Propeller-Rudder System in Oblique Flow. International Journal of Naval Architecture and Ocean Engineering, vol. 10, 69-84, DOI: 10.1016/j. ijnaoe.2017.03.005
18. Troost, L. (1938). Open Water Test series with Modern Propeller Forms. Trans. NECIES, vol. 54

19. Troost, L. (1940). Open Water Test Series with Modern Propeller Forms II, Three Bladed Propellers. Trans. NECIES

20. Troost, L. (1951). Open Water Test Series with Modern Propeller Forms III, Two Bladed and Five Bladed Propellers - Extension of Three and Four Bladed B-Series. Trans. NECIES, vol. 67.

21. Van Lammeren, W. P. A., Van Manen, J. D., Oosterveld, M. W. C. (1969). The Wageningen B-Screw Series. Trans. SNAME.

22. Van Gent, W., Van Oossanen, P. (1973). Influence of Wake on Propeller Loading and Cavitation. in 2nd Lips Propeller-Symposium.

23. Van Oossanen, P. (1974). Calculation of Performance and Cavitation Characteristics of Propellers including Effects of Non-uniform Flow and Viscosity. Ph.D Thesis, Delft University of Technology.

24. BKI. (2018). Rules for Classification and Construction - Rules for Hull. Indonesia Classification Bureau.

25. Gaafary, M. M., El-Kilani, H. S., Moustafa, M. M. (2011). Optimum Design of B-series Marine Propellers. Alexandria Engineering Journal, vol. 50, 13-18, DOI: 10.1016/j.aej.2011.01.001 